\title{
Fucosylated Hybrid-Type N-Glycans on the Secreted Human Epidermal Growth Factor Receptor from Swainsonine-Treated A431 Cells
}

\author{
Corné J . M. Stroop,* Wolfgang Weber,† Manfred Nimtz,† Ricardo Gutiérrez Gallego,* \\ J ohannis P. Kamerling,* and J ohannes F. G. Vliegenthart*,1 \\ *Bijvoet Center, Department of Bio-Organic Chemistry, Utrecht University, P.O. Box 80075, 3508 TB Utrecht, \\ The Netherlands; †I nstitut für Physiologische Chemie, Universitätskrankenhaus E ppendorf, \\ D-20246 Hamburg, Germany; and ¥Gesel Ischaft für Biotechnologische Forschung mbH, \\ Structure Research, Mascheroder Weg 1, D-38124 Braunschweig, Germany
}

Received August 19, 1999, and in revised form November 12, 1999

\begin{abstract}
N-Glycans linked to the human secreted form of epidermal growth factor receptor were isolated from A431 cells after swainsonine treatment. Analysis of the oligosaccharides by ${ }^{1} \mathrm{H}$ NMR spectroscopy and mass spectrometry shows the presence of oligomannoseand ( $\alpha 2-3)$-sialylated hybrid-type glycans. The major hybrid-type oligosaccharide chains are fucosylated at the Asn-bound GIcNAc residue. Smaller amounts of the hybrid-type structures are also fucosylated at peripheral GICNAc residues, constituting the sialyl-Le $e^{x}$ antigen. No complex-type glycans are found, suggesting the absence of $\alpha$-mannosidase III. An assay for $\alpha$-mannosidase III on the A431 cells in the absence and presence of $6 \mu \mathrm{M}$ swainsonine shows that $\mathrm{Man}_{5} \mathrm{GICNAC}_{2}$ is not converted into $\operatorname{Man}_{3} \mathrm{GICNAC}_{2}$, thereby confirming that these cells do not contain $\alpha$-mannosidase III activity. ๑ 2000 Academic Press

Key Words: hybrid-type N-glycans; $\alpha$-mannosidase III; sialyl-Le ${ }^{x}$; human E GFR; A431; swainsonine.
\end{abstract}

Protein glycosylation, often shown to be essential for the function and conformation of a glycoprotein, mostly exhibits (micro)heterogeneity, i.e., various ensembles of glycans can be present on one protein at the different glycosylation sites. Inhibition of the processing of the glycans will leave a still heterogeneous glycoprotein, but with a less diverse ensemble of oligosaccharides. This can be beneficial to obtain compounds that are more suitable for X-ray crystallography than regular

\footnotetext{
${ }^{1}$ To whom correspondence should be addressed. Fax: +31-302540980.
}

glycoproteins, because the growing of high-quality single arystals is often hindered by the glycan heterogeneity.

The use of the glycoprotein processing inhibitor swainsonine has been shown to be a tool for the improvement of crystallization of glycosylated proteins (W. Weber, unpublished work). This may provide the possibility of investigating a complete glycoprotein instead of its nonglycosylated form. The point of action of swainsonine in the biosynthetic pathway, inhibition of $\alpha$-mannosidase II in the medial Golgi (1), allows the processing to oligomannose- and hybrid-type glycans, but not to complex-type glycans (2). $\alpha-1,6-\mathrm{F}$ ucosyltransferase is not affected, so the hybrid-type glycans can be fucosylated at the Asn-bound $\operatorname{GICNAc}(3,4)$.

Recently, a bypass was postulated in which an $\alpha$-mannosidase III in mouse splenocytes and fibroblasts converts $\mathrm{Man}_{5} \mathrm{GICNAC}_{2}$ into $\mathrm{Man}_{3} \mathrm{GICNAC}_{2}$, thereby circumventing the action of $\alpha$-mannosidase II. $\mathrm{Man}_{3} \mathrm{GICNAC}_{2}$ is a substrate for GICNAc-transferase I and the product can be further enlarged to complextype glycans (5). Characteristically, $\alpha$-mannosidase III is insensitive toward low concentrations of swainsonine that block $\alpha$-mannosidase II (6).

Here, the analysis of the N-linked oligosaccharide chains is presented for the human secreted epidermal growth factor receptor (sEGFR) ${ }^{2}$ isolated from swain-

\footnotetext{
${ }^{2}$ Abbreviations used: sEGFR, secreted epidermal growth factor receptor; PNGase F, peptide-N-glycosidase F ; AAA, Aleuria aurantia agglutinin; PBS, phosphate-buffered saline; HPAEC, high-pH anionexchange chromatography; PAD, pulsed amperometric detection; MALDI-TOF-MS, matrix-assisted laser desorption ionization-timeof-flight-mass spectrometry; ESI-MS-MS, el ectrospray ionizationtandem mass spectrometry; BHK, baby hamster kidney.
} 
sonine-treated A431 cells, and the $\alpha$-mannosidase III activity of these cells was investigated.

\section{MATERIALS AND METHODS}

Monosaccharide analysis. The purification of swainsonine-modified SEGFR (Institut für Physiologische Chemie, UKE Hamburg) by immunoaffinity chromatography was performed as described before (7). Prior to monosaccharide analysis, the sample was desalted by dialysis against water overnight using Medicell 256K 01 tubing. For the analysis, $200 \mu \mathrm{g}$ SEGFR glycoprotein was lyophilized and subjected to a $24-\mathrm{h}$ treatment with methanolic $1 \mathrm{M} \mathrm{HCl}$ at $85^{\circ} \mathrm{C}$. The neutralized (methyl ester) methyl glycoside mixture was re-N-acetylated (50 $\mu$ l acetic anhydride, overnight), followed by trimethylsilyIation with hexamethyldisilazane:trimethylchlorosilane:pyridine, 1:1:5. Monosaccharide analysis was carried out by GLC on a DB-1 column (30 $\mathrm{m} \times 0.32 \mathrm{~mm}$, J \& W Scientific), using a Varian 3700 gas chromatograph $\left(140-240^{\circ} \mathrm{C}\right.$ at $\left.4^{\circ} \mathrm{C} / \mathrm{min}\right)$. The molar ratio of GIcNAC was corrected for its stable linkage to Asn (8).

Liberation and isolation of $\mathrm{N}$-linked oligosaccharide chains. The $\mathrm{N}$-linked oligosaccharide chains of swainsonine-modified SEGFR were liberated by treatment with peptide-N-glycosidase F (PNGase $F$, Boehringer-Mannheim). Desalted SEGFR $(600 \mu \mathrm{g})$ in sodium phosphate buffer (100 mM, pH 7.0) was denatured with SDS [1:1.3 (w/w) of SEGFR to SDS] and reduced with $1 \%(\mathrm{v} / \mathrm{v})$ 2-mercaptoethanol by a 5 -min incubation at $95^{\circ} \mathrm{C}$. After cooling down to room temperature, decanoyl-N-methylglucamide (MEGA-10, BoehringerMannheim) was added in a 2 to $1(\mathrm{w} / \mathrm{w})$ ratio to SDS. This was followed by a 24-h incubation with 1 U PNGase F at room temperature in an end-over-end mixer. A fresh aliquot of $1 \cup$ PNGase $F$ was added for an overnight continuation of the incubation. The incubation was monitored with SDS-PAGE, on a $10 \%$ slab gel, and Coomassie brilliant blue staining.

The de-N-glycosylated protein was precipitated by addition of 4 vol of ice-cold methanol to the incubation mixture. The mixture was kept on ice for $1 \mathrm{~h}$, followed by centrifugation at $2000 \mathrm{rpm}$ for $10 \mathrm{~min}$ (9). The pellet was washed with $1 \mathrm{ml}$ methanol. The supernatants, containing the released carbohydrate chains, were concentrated under reduced pressure and desalted on three connected HiTrap desalting columns ( $3 \times 5 \mathrm{ml}$, Pharmacia Biotech), eluting with $5 \mathrm{mM}$ $\mathrm{NH}_{4} \mathrm{HCO}_{3}$ at a flow rate of $3 \mathrm{ml} / \mathrm{min}$. Carbohydrate-containing fractions (300-M Hz ${ }^{1} \mathrm{H}$ NMR analysis) were lyophilized and fractionated on a Resource Q anion-exchange column (1 ml, Pharmacia Biotech), using a Pharmacia FPLC system. Elutions were carried out with 2 $\mathrm{ml}$ water, followed by an $8-\mathrm{ml}$ linear gradient of 0 to $50 \mathrm{mM} \mathrm{NaCl}$, subsequently, an 8-ml gradient of 50 to $250 \mathrm{mM} \mathrm{NaCl}$, and finally a 4-ml gradient of 250 to $500 \mathrm{mM} \mathrm{NaCl}$. Collected fractions were lyophilized and desalted on HiTrap. The various chromatographic steps were monitored at $214 \mathrm{~nm}$.

AAA Sepharose chromatography. Lectin AAA (Aleuria aurantia agglutinin, Boehringer-Mannheim Biochemica) was coupled to CNBr-activated Sepharose (Pharmacia Biotech) as described by Pharmacia. Swelled CNBr-activated Sepharose $(0.5 \mathrm{ml})$ was rinsed with $30 \mathrm{ml}$ ice-cold $1 \mathrm{mM} \mathrm{HCl}$ and added to $5 \mathrm{mg} \mathrm{AAA} \mathrm{lectin} \mathrm{in} 700$ $\mu$ l $0.36 \mathrm{M} \mathrm{NaCl}$ containing $0.07 \mathrm{M} \mathrm{NaHCO}_{3}$. The Sepharose/lectin mixture was gently shaken for $1 \mathrm{~h}$ at room temperature. To block the remaining active sites of Sepharose, the gel was incubated overnight in $0.1 \mathrm{M}$ Tris- $\mathrm{HCl}$ buffer, $\mathrm{pH} 8.0$, at $4^{\circ} \mathrm{C}$. The gel was brought into a column and washed three times with a cycle of $5 \mathrm{ml} 0.5 \mathrm{M} \mathrm{NaCl}$ containing $0.1 \mathrm{M} \mathrm{NaOAC}, \mathrm{pH} 4.0$, and $5 \mathrm{ml} 0.5 \mathrm{M} \mathrm{NaCl}$ containing 0.1 M Tris- $\mathrm{HCl}, \mathrm{pH}$ 8.0.

After equilibration of the AAA Sepharose column with phosphatebuffered saline (PBS; $0.01 \mathrm{M}$ phosphate buffer containing $2.7 \mathrm{mM}$ $\mathrm{KCl}$ and $0.137 \mathrm{M} \mathrm{NaCl}, \mathrm{pH}$ 7.4), the neutral Resource $\mathrm{Q}$ glycan fraction derived from swainsonine-modified SEGFR was applied to the column. Using a flow of $15 \mathrm{ml} / \mathrm{h}$ at room temperature, the unbound fraction was eluted with $30 \mathrm{ml}$ PBS and the bound fraction was eluted with $24 \mathrm{ml}$ PBS containing $50 \mathrm{mM}$ L-Fuc (Fluka BioChemika).

HPAEC profiling. Profiling of oligomannose-type glycans was performed with high-pH anion-exchange chromatography with pulsed amperometric detection (PAD). The unbound AAA Sepharose fraction was applied to a Dionex CarboPac PA-100 pellicular anionexchange column $(0.4 \times 25 \mathrm{~cm})$ in a Dionex BioLC system with a PAD-2 detector. Elutions were carried out with a linear gradient of 10 to $62.5 \mathrm{mM} \mathrm{NaOAc}$ in $20 \mathrm{ml} 0.1 \mathrm{M} \mathrm{NaOH}$, followed by a linear gradient of 62.5 to $500 \mathrm{mM} \mathrm{NaOAcin} 5 \mathrm{ml} 0.1 \mathrm{M} \mathrm{NaOH}$, at a flow rate of $1 \mathrm{ml} / \mathrm{min}$. Pulsed amperometric detection was carried out using the following pulse potentials and duration settings: $\mathrm{E}_{1}=0.05 \mathrm{~V}, 300$ $\mathrm{ms} ; \mathrm{E}_{2}=0.65 \mathrm{~V}, 60 \mathrm{~ms} ; \mathrm{E}_{3}=-0.95 \mathrm{~V}, 180 \mathrm{~ms}$.

Methylation analysis. Oligosaccharides were permethylated, purified on Sepharose LH-20 (run with ethyl acetate), hydrolyzed, reduced, and peracetylated as described (10). Separation and identification of partially methylated alditol acetates were performed on a Finnigan gas chromatograph (Finnigan MAT Corp.), equipped with a 30-m DB-5 capillary column, connected to a Finnigan GCQ ion-trap mass spectrometer (Structure Research, GBF Braunschweig).

Mannosidase activity assay. Man $_{5}$ GICNAC $_{2}$ (Man( $\left.\alpha 1-3\right)\{$ Man $(\alpha 1-3)[M a n(\alpha 1-6)$ ]Man $(\alpha 1-6)$ \}M an $(\beta 1-4)$ GICNAc( $\beta 1-4)$ GICNAC) was 2-aminobenzamide-label ed as described (11) with the following modifications: during the chromatographic recovery QMA paper (Whatmann) was used instead of 3MM to improve the overall yield, and the nonglycan material was eluted using acetonitrile instead of n-butanol:ethanol:water (4:1:1).

A431 variant cells (Institut für Physiologische Chemie, UKE Hamburg) were grown in monolayers on polystyrene culture dishes in serum-free Dulbecco's modified Eagle's/F-12 medium, supplemented with $0.5 \mathrm{mg} / \mathrm{liter}$ human transferrin, $50 \mathrm{nM}$ hydrocortisone, 0.025 $\mathrm{mg} / \mathrm{liter}$ sodium selenite, and $0.1 \mathrm{~g} / \mathrm{liter}$ bovine serum albumin, at $37^{\circ} \mathrm{C}$ under $5 \% \mathrm{CO}_{2}$ (7). After removal of the medium, the cells were washed twice with $0.9 \% \mathrm{NaCl}$. The cells were then scraped from the dishes with a rubber policeman and homogenized. Following a centrifugation of $1500 \mathrm{rpm}$ for $5 \mathrm{~min}$, the supernatant was removed and the cells were resuspended in buffer $\mathrm{P}$ [250 mM Mes (pH 6.5), $10 \mathrm{mM}$ $\mathrm{MgCl}_{2}, 5 \mathrm{mM} \mathrm{CaCl}_{2}, 1 \mathrm{mM} \mathrm{CoCl}, 10 \%$ glycerol, $0.25 \%$ Triton X-100, $28 \mu \mathrm{g} / \mathrm{ml}$ Trasylol (Bayer), and $1 \mathrm{mM}$ phenylmethanesulfonyl fluoride]. The cells were counted with a Coulter counter.

E ach cell sample consisted of $5 \times 10^{6}$ cells in $100 \mu$ l buffer $P$. In one series of incubations $(1,8,24 \mathrm{~h})$, swainsonine was added at a final concentration of $6 \mu \mathrm{M}$. The substrate, 2-amino-benzamide-labeled $\mathrm{Man}_{5} \mathrm{GICNAC}_{2}\left(\mathrm{Man}_{5} \mathrm{GICNAC}_{2}-2 \mathrm{AB}\right)$, was added to the cell samples at a concentration of about $1 \mathrm{mM}$. The incubations at $37^{\circ} \mathrm{C}$ were stopped by heating at $95^{\circ} \mathrm{C}$ for $5 \mathrm{~min}$. The samples were centrifuged and the supernatant was passed over a $0.5-\mathrm{ml}$ detergent-removing column (Extracti-Gel D, Pierce), desalted on HiTrap $(4 \times 5 \mathrm{ml})$, and lyophilized. Normal-phase separation of the labeled glycans was performed according to (12) starting with a linear gradient of 35\% A (50 mM ammonium formate, $\mathrm{pH} 4.4$ ) and 65\% B (acetonitrile) to 58\% $\mathrm{A}$ at a flow rate of $0.4 \mathrm{ml} / \mathrm{min}$ over $92 \mathrm{~min}$ and 58 to $100 \% \mathrm{~A}$ over the next $3 \mathrm{~min}$. The HPLC system used was a Waters 2690 XE instrument equipped with a GlycoSep- $\mathrm{N}$ column (Oxford GlycoSciences) and a Waters 474 scanning fluorescence detector.

Mass spectrometry. For analysis by MALDI-TOF-MS (matrixassisted laser desorption ionization-time-of-flight-mass spectrometry), 2,5-dihydroxybenzoic acid ( $10 \mathrm{mg} / \mathrm{ml} 10 \%$ ethanol in water) was used as UV-absorbing matrix. Solutions of permethylated oligosaccharides in methanol were mixed with the same volume of matrix. One microliter of the sample was spotted onto a stainless steel target and dried at room temperature. The concentrations of the analyte mixtures were approximately $10 \mathrm{pmol} / \mathrm{ml}$.

Measurements were performed on a Bruker Reflex MALDI-TOF mass spectrometer (Structure Research, GBF Braunschweig) with implemented delayed extraction technique using a $\mathrm{N}_{2}$ laser $(337 \mathrm{~nm}$ ) 
TABLE I

Monosaccharide Composition of sEGFR from Swainsonine-Treated A431 Cells

\begin{tabular}{cc}
\hline Monosaccharide & Molar ratios $^{\mathrm{a}}$ \\
\hline Fuc & 0.8 \\
Man & 3.0 \\
Gal & 0.7 \\
GIcNAc & 2.5 \\
GalNAc & 0.1 \\
Neu5Ac & 0.7 \\
\hline
\end{tabular}

${ }^{a}$ Average of four GLC runs; Man is taken as 3.0.

with 3-ns pulse width and 107-108 W/ $\mathrm{cm}^{2}$ irradiance at the surface $\left(0.2 \mathrm{~mm}^{2}\right)$. Spectra were recorded at an acceleration voltage of $20 \mathrm{kV}$ using the reflectron mode for enhanced resolution.

For electrospray ionization-tandem mass spectrometry (ESI-MSMS), a Finnigan MAT TSQ 700 triple-quadrupole mass spectrometer (Structure Research, GBF Braunschweig) equipped with a nanospray ion source (Protana) was used. The permethylated samples were dissolved in methanol saturated with $\mathrm{NaCl}$ (about $10 \mathrm{pmol} / \mathrm{ml}$ ) and approximately $3 \mu \mathrm{l}$ of solution was filled into gold-coated nanospray glass capillaries (Protana). The tip of the capillary was placed directly in front of the entrance hole of the heated transfer line of the mass spectrometer and a voltage of $800 \mathrm{~V}$ applied leading to flow rates of approximately $50 \mathrm{nl} / \mathrm{min}$. For collision-induced dissociation experiments, parent ions were selectively transmitted by the first mass analyzer and directed into the collision cell (with argon as collision gas) with a kinetic energy set around $-58 \mathrm{eV}$.

${ }^{1} \mathrm{H}$ NMR spectroscopy. Oligosaccharide samples were exchanged twice in ${ }^{2} \mathrm{H}_{2} \mathrm{O}$ (99.9 atom\% ${ }^{2} \mathrm{H}$, I sotec) with intermediate lyophilization and dissolved in 99.96 atom\% ${ }^{2} \mathrm{H}_{2} \mathrm{O}$ (I sotec). 1D spectra were recorded on a Bruker AC-300 (Department of Organic Chemistry, Utrecht University), a Bruker AMX-500, or a Bruker AMX-600 spectrometer (Bijvoet Center, Department of NMR Spectroscopy) at a probe temperature of $300 \mathrm{~K}$. The spectra with spectral widths of 10 ppm for 300, 500, and $600 \mathrm{MHz}$ were recorded in $8 \mathrm{~K}$ complex data sets, using a WEFT pulse sequence to suppress the ${ }^{2} \mathrm{HOH}$ signal (13). Chemical shifts were expressed in ppm relative to internal acetate ( $\delta$ 1.908) or internal acetone ( $\delta 2.225)$.

\section{RESULTS}

Isolation and analysis of the $\mathrm{N}$-linked oligosaccharide chains. Purified SEGFR (7) from swainsoninetreated A431 cells was subjected to monosaccharide analysis (Table I), revealing the presence of Man, Fuc, Gal, GIcNAc, GalNAc, and Neu5Ac. The amounts of the monosaccharides, when compared to mannose, are indicative of a large amount of oligomannose-type and/or hybrid-type glycans.

PNGase F-liberated N-linked glycans were separated on Resource $\mathrm{Q}$ according to their number of Neu5Ac residues. Swainsonine-modified SEGFR contained neutral (S-QN), monosialylated (S-Q1), and disialylated (S-Q2) glycans (Table II).

${ }^{1} \mathrm{H}$ NMR spectroscopy. Fraction S-QN was analyzed by $1 \mathrm{D}{ }^{1} \mathrm{H}$ NMR spectroscopy (Table III). The chemical shifts of the NAc protons ( $\delta$ 2.0-2.1) clearly
TABLE II

Anion-Exchange Chromatography of Glycans Liberated from Swainsonine-M odified SEGFR

\begin{tabular}{cc}
\hline Resource Q $^{\text {fraction }}{ }^{\mathrm{a}}$ & Amount $^{(\%)^{\mathrm{b}}}$ \\
\hline S-QN & 45 \\
S-Q1 & 27 \\
S-Q2 & 27 \\
\hline
\end{tabular}

a S-QN, neutral; S-Q1, monosialylated, etc.

${ }^{\mathrm{b}}$ The percentage of a glycan fraction of the total $\mathrm{N}$-glycan pool was calculated from the UV absorption at $214 \mathrm{~nm}$.

show the structural differences between the normal (14) and the swainsonine-modified SEGFR glycans. Fucosylation of GICNAC-1 (Fuc $\mathrm{H}-1, \delta$ 4.890) has a specific influence on the shift of the GICNAc-2 NAc signal. The composition of the branches linked to the $\mathrm{Man}_{3} \mathrm{GICNAC}_{2}$ core also affects the position of the NAC signal of GICNAc-2: $\delta 2.078$ for nonfucosylated complextype glycans (15), $\delta 2.064$ for nonfucosylated oligomannose- and hybrid-type glycans $(16,17)$, and $\delta 2.094$ for complex-type glycans with core fucosylation (9). Hybrid-type structures with two mannose residues linked to Man-4' and a Fuc residue at GICNAc-1 have not yet been characterized with ${ }^{1} \mathrm{H}$ NMR spectroscopy. Since the attachment of Fuc in ( $\alpha 1-6)$ linkage to GICNAc-1 of a complex-type structure results in a downfield chemical shift change of $\sim 0.016$ ppm for GICNAc-2 NAc, it can be expected that fucosylation of GICNAc-1 of a hybrid-type glycan will cause a similar change for the GICNAc-2 NAC signal $(\delta \approx 2.064 \rightarrow \delta \approx 2.078$ ). In hybrid-type structures, only GICNAc-5 on the $(\alpha 1-3)$ branch is present. Because the signal for GICNAc-5' (NAc, $\delta 2.039$ ) in complex-type structures would coincide with that of GICNAc-1, the signal intensity $\left({ }^{2.039}=\right.$ $\left.\right|^{2.064}+\left.\right|^{2.078}$ ) indicates the absence of GICNAc-5' and, therefore, complex-type glycans in fraction S-QN. Taking into account these considerations, fraction S-QN

\section{TABLE III}

${ }^{1} \mathrm{H}$-Chemical Shifts of N-Acetyl Groups of GICNAC and Neu5Ac Residues in N-Linked Glycans from Swainsonine-M odified SEGFR

\begin{tabular}{lccc}
\hline Residue & \multicolumn{3}{c}{ Chemical shift (ppm) } \\
\cline { 2 - 4 } & S-QN & S-Q1 & S-Q2 \\
\hline GIcNAc-1 & 2.039 & 2.040 & 2.040 \\
GIcNAc-2 & 2.078 & 2.078 & 2.076 \\
GIcNAc-5 & 2.064 & - & - \\
GICNAc-7 & 2.048 & 2.049 & 2.049 \\
Neu5Ac & - & - & 2.079 \\
\hline
\end{tabular}

\footnotetext{
a Signal stemming from two N-acetyl groups.
} 


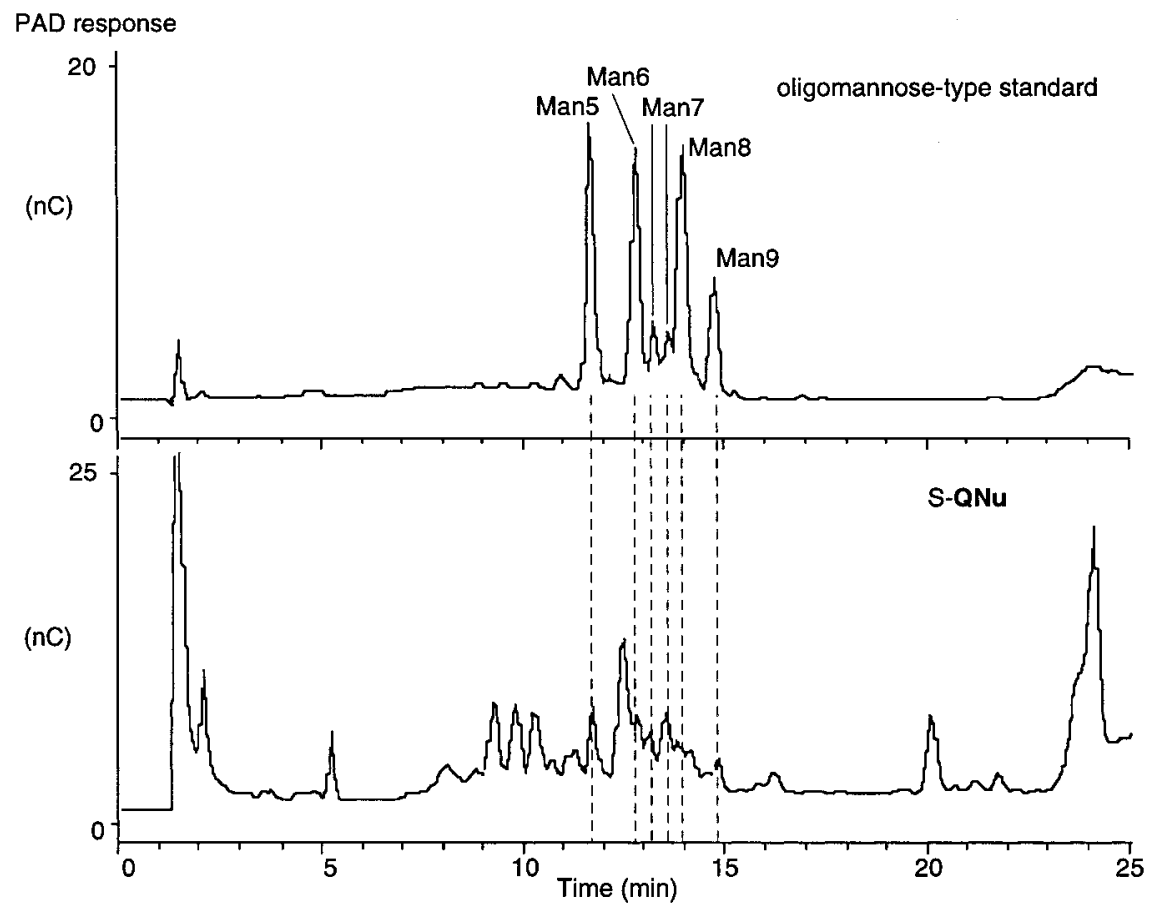

FIG. 1. HPAEC profile of an oligomannose-type glycan standard (all structures end in two GICNAc residues at the reducing end) and the AAA Sepharose-unbound fraction (S-QNu) of the neutral glycans from swainsonine-modified sEGFR.

consists of oligomannose and (core-fucosylated) hybridtype structures.

S-Q1 and S-Q2 show no GICNAC-5' NAC signal $\left(\mathrm{I}^{2.040}=\mathrm{I}^{2.078 / 2.076}\right)$, so that the NAc signal near $\delta 2.078$ suggests that these fractions consist of hybrid-type oligosaccharides with a Fuc residue linked to GlcNAc-1. Core fucosylation is confirmed by $\mathrm{CH}_{3}$ signals at $\delta 1.211$ and $\delta 1.221$, representing an ( $\alpha 1-6)$-linked Fuc residue. Neu5Ac (NAc signal at $\delta 2.033$, Table III) is $(\alpha 2-3)$-linked in the hybrid-type glycans $(\mathrm{H}-3 \mathrm{a}, \delta$ 1.80; and $\mathrm{H}-3 \mathrm{e}, \delta 2.76)$.

Owing to the limited amount of sample available, HPAEC profiling, methylation analysis, and mass spectrometry were used to gain more detailed information on the oligosaccharide structures.

AAA Sepharose chromatography and HPAEC profiling. To verify the composition of fraction S-QN, the oligosaccharides were separated on Sepharose loaded with the ( $\alpha 1-6)$-F uc-specific AAA lectin, giving rise to an unbound fraction (S-QNu) and a bound fraction (S-QNb) that eluted with $50 \mathrm{mM}$ L-Fuc. In view of the NMR data of fraction S-QN, fraction S-QNb comprises the core-fucosylated hybrid-type structures. Based on the intensities of the NMR peaks at $\delta 2.064$ and $\delta$ 2.078, the ratio of S-QNu and S-QNb amounts 55:45.

Fraction S-QNu, containing glycans without core fucosylation, was applied to HPAEC. Elution under the same conditions as a standard mixture of oligomannose-type structures (Fig. 1) indicates the presence of components ranging from $\mathrm{Man}_{5} \mathrm{GICNAC}_{2}$ to $\mathrm{Man}_{9} \mathrm{GICNAC}_{2}$ (Schemel). The origin of the other peaks in Fig. 1 is undear and MALDI-TOF-MS did not provide any clues concerning the identity of those peaks.

Mass spectrometry. The reduced and permethylated fraction S-Q1 (Fig. 2) shows one major sodiated molecular ion on positive-ion mode MALDI-TOF-MS at $\mathrm{m} / \mathrm{z} 2582$ [Neu5AcHex ${ }_{6} \mathrm{HexNAc}_{2} \mathrm{dHexHexNAc-ol} \mathrm{+}$ $\mathrm{Na}$ ] and two minor sodiated molecular ions at $\mathrm{m} / \mathrm{z} 2407$ $\left[\mathrm{Neu} 5 \mathrm{AcH} \mathrm{ex}_{6} \mathrm{HexNAC}_{2} \mathrm{HexNAc-ol}+\mathrm{Na}\right.$ ] and $\mathrm{m} / \mathrm{z} 2756$ [Neu5AcH ex ${ }_{6} \mathrm{HexNAc}_{2} \mathrm{dHex}_{2} \mathrm{HexNAc-O}+\mathrm{Na}$ ]. Taking into account the NMR data of fraction S-Q1, it implies that the major compound is a core-fucosylated hybridtype glycan with one sialylated branch. The minor component at $\mathrm{m} / \mathrm{z} 2407$ represents a nonfucosylated hybrid-type structure. The second minor compound, at $\mathrm{m} / \mathrm{z} 2756$, contains an extra Fuc residue, proposed to be linked to the GICNAc residue in the ( $\alpha 1-3)$-linked branch, constituting a hybrid-type glycan with a sialylL $\mathrm{e}^{\mathrm{x}}$ determinant (Scheme I). This proposal is confirmed by methylation analysis (Table IV) showing the presence of 3,4-disubstituted GICNAc. Methylation analysis was used to calculate the relative amounts of oligosaccharides presented in Scheme I. Integration of the MALDI-TOF peaks for the S-Q1 fraction in Fig. 2 agrees well with these relativeamounts. Further support for the structures is found in the ESI-MS results: doubly charged (disodium adducts) molecular ions are present at $\mathrm{m} / \mathrm{z} 1214$ [Neu5AcHex ${ }_{6} \mathrm{HexNAc}_{2} \mathrm{H}$ exNAc-ol $+2 \mathrm{Na}$ ], m/z 


\section{SCHEME I}

N-Linked Oligosaccharides on SEGFR from Swainsonine-Treated A431 Cells

Fraction

S-QN ${ }^{\text {a }}$

Structure

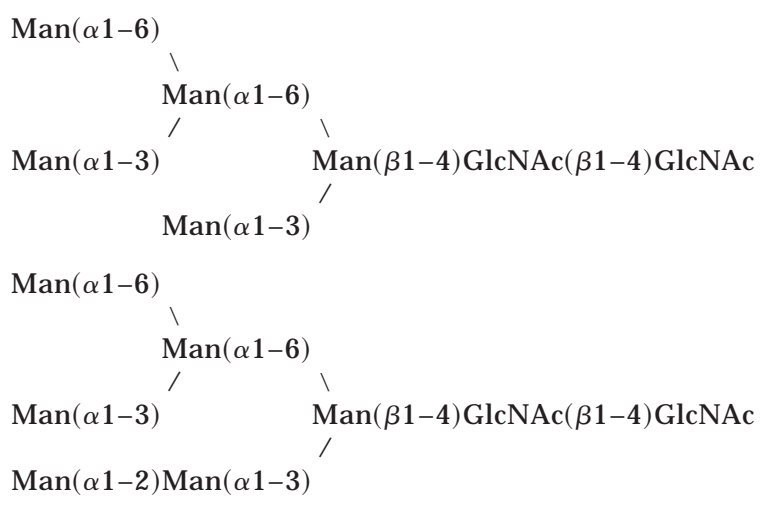



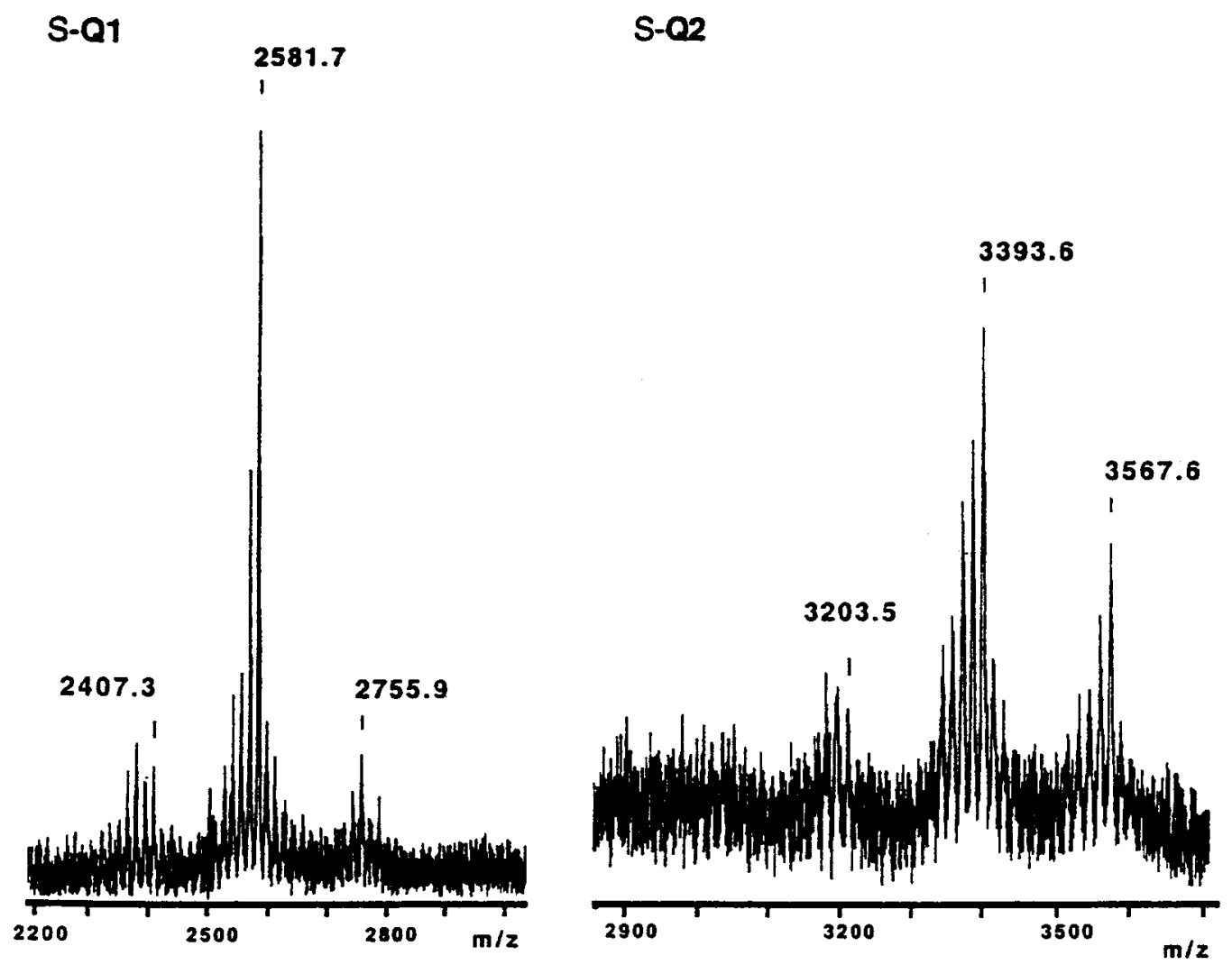

FIG. 2. MALDI-TOF mass spectra of the reduced and permethylated sialylated hybrid-type oligosaccharide fractions S-Q1 and S-Q2 from swainsonine-modified SEGFR. The peak pattern is typical for partial undermethylation.

$\mathrm{Hex}_{7} \mathrm{HexNAC}_{3} \mathrm{dHex}_{2} \mathrm{HexNAc-ol}+\mathrm{Na}$. The peak present at $\mathrm{m} / \mathrm{z} 3204$ represents a sodiated molecular

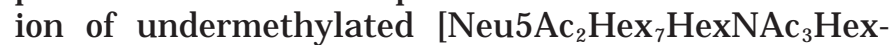
$\mathrm{NAc}-\mathrm{Ol}+\mathrm{Na}$ ]. These molecular ions suggest the presence of hybrid-type structures, analogous to S-Q1, with zero to two Fuc residues and an additional sialylated

\section{TABLE IV}

Methylation Analysis of N-Linked Glycans from Swainsonine-Modified SEGFR

\begin{tabular}{lll}
\hline Derivative $^{\mathrm{a}}$ & S-Q1 & S-Q2 \\
\hline Fuc(1- & 1.1 & 1.2 \\
-3)Gal(1- & 1.0 & 2.0 \\
Man(1- & 2.0 & 2.0 \\
-2)Man(1- & 1.0 & $0.2^{\mathrm{c}}$ \\
-2,4)Man(1- & $0.1^{\mathrm{b}}$ & 0.9 \\
-3,6)Man(1- & 2.0 & 2.0 \\
-4)GICNAc & 0.1 & 0.1 \\
-4,6)GICNAc & 0.9 & 0.9 \\
-4)GICNAC(1- & 1.6 & 2.5 \\
-3,4)GICNAc(1- & 0.2 & 0.4 \\
\hline
\end{tabular}

${ }^{a}$ Fuc(1-, 1-O-acetyl-2,3,4-tri-O-methyl-fucitol, etc.

${ }^{b}$ Possible contamination by fraction S-Q2.

c Possible contamination by fraction S-Q1.
$\mathrm{N}$-acetyllactosamine antenna attached to 0-4 of the ( $\alpha 1-3$ )-linked core Man residue (Schemel). The latter is supported by methylation analysis showing the presence of the 2,4-disubstituted Man derivative (Table IV).

Mannosidase activity assay. Swainsonine treatment of the A431 cells fully blocked $\alpha$-mannosidase II, since no complex-type glycans are found on SEGFR. The absence of complex-type glycans implies also that no $\alpha$-mannosidase III activity is present. This implication was tested by incubating the cells with 2-aminobenzamide-labeled $\mathrm{Man}_{5} \mathrm{GICNAC}_{2}\left(\mathrm{Man}_{5} \mathrm{GICNAC}_{2}-2 \mathrm{AB}\right)$ in the absence and presence of $6 \mu \mathrm{M}$ swainsonine, a concentration that blocks $\alpha$-mannosidase II but not $\alpha$-mannosidase III (6).

HPLC analysis of the incubation mixture containing swainsonine shows that the substrate is not converted into $\mathrm{Man}_{3} \mathrm{GICNAC}_{2}-2 \mathrm{AB}$ nor into $\mathrm{Man}_{4} \mathrm{GICNAC}_{2}-2 \mathrm{AB}$. However, in the absence of swainsonine a conversion into $\mathrm{Man}_{4} \mathrm{GICNAC}_{2}-2 \mathrm{AB}$ is visible in the HPLC profiles after 8 and $24 \mathrm{~h}$ of incubation (Fig. 4), al beit rather low. Thus, even in the absence of its inhibitor the action of $\alpha$-mannosidase II was prevented, which can be explained by the fact that $\alpha$-mannosidase II acts after the addition of GICNAc to Man-4. This extension was not possible because the assay buffers lacked UDP-GIc- 


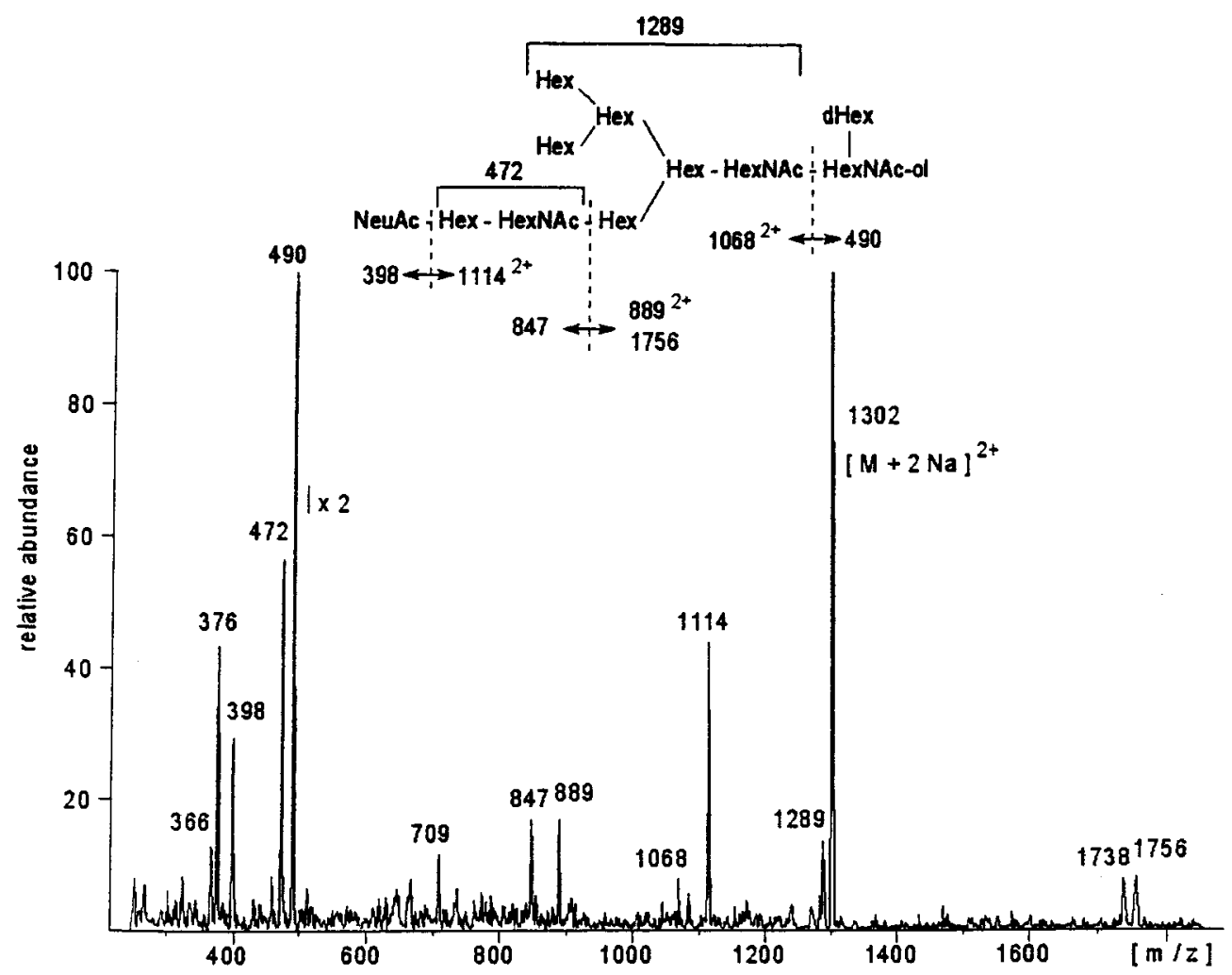

FIG. 3. Daughter-ion spectrum of the doubly charged molecular ion at $\mathrm{m} / \mathrm{z} 1302$ (disodium adduct) of the major component in the reduced and permethylated monosialylated hybrid-type glycan fraction S-Q1 from swainsonine-modified sEGFR in the ESI mass spectrum. The fragmentation pattern is explained in the text and in the inserted fragmentation scheme.

NAc. The absence of any swainsonine-insensitive mannosidase activity is clear, especially when compared to the low activity in mosquito Aedes aegypti cells (18) for which the $\alpha$-mannosidase III activity was concluded to be absent (6).

\section{DISCUSSION}

Swainsonine is known to prevent the conversion of oligomannose-type glycans into complex-type glycans resulting in the production of hybrid-type glycans (19, 20). This effect was clearly demonstrated by our analysis of the oligosaccharide chains of SEGFR from swainsonine-treated A431 cells. Most of the hybridtype structures, as they are presented in Scheme I, correspond to the glycoprotein glycan structures found in swainsonine-treated baby hamster kidney (BHK) cells (21). However, in addition to core fucosylation, in about $10-20 \%$ of the swainsonine-modified SE GF R glycans, Fuc is ( $\alpha 1-3)$-linked to GICNAc of N-acetyllactosamine, resulting in a sialyl-L $\mathrm{e}^{\mathrm{x}}$ antigen. Although the blockage of $\alpha$-mannosidase II has no effect on the processing of the ( $\alpha 1-3)$-linked arms, hybrid-type glycans terminated in a sialyl-Le $e^{x}$ antigen have not yet been published.
The monosaccharide analysis shows the presence of GalNAc, which is not found in the charged fractions. On the basis of the oligosaccharides characterized on normal sEGFR (14), it is likely that the hybrid-type structures in the swainsonine-modified SEGFR fraction S-QN include GalNAc in blood group A-related determinants.

The absence of complex-type structures may seem evident from the inhibition of $\alpha$-mannosidase II, but in recent years the presence of another $\alpha$-mannosidase has been shown to exist in rats and mice $(5,6)$. This so-called $\alpha$-mannosidase III is stabilized by $\mathrm{Co}^{2+}$ and is only fully inhibited by swainsonine at a concentration of about $1 \mathrm{mM}$ (6). The sEGFR analyzed in this study was produced in A431 cells in the presence of $\mathrm{Co}^{2+}$ and the swainsonine concentration was $6 \mu \mathrm{M}$ only. So, if $\alpha$-mannosidase III had been present in A431 cells, it should have been active. The absence of complex-type structures, therefore, indicates that $\alpha$-mannosidase I II is not present in A431 cells. To test this hypothesis the cells were incubated with $\mathrm{Man}_{5} \mathrm{GICNAC}_{2}-2 \mathrm{AB}$ under the same conditions, including $\mathrm{CO}^{2+}$, and $0.25 \%$ Triton X-100 was added to make the substrate accessible to the Golgi lumen. It shows that virtually no activity is present in the human A431 cells. 

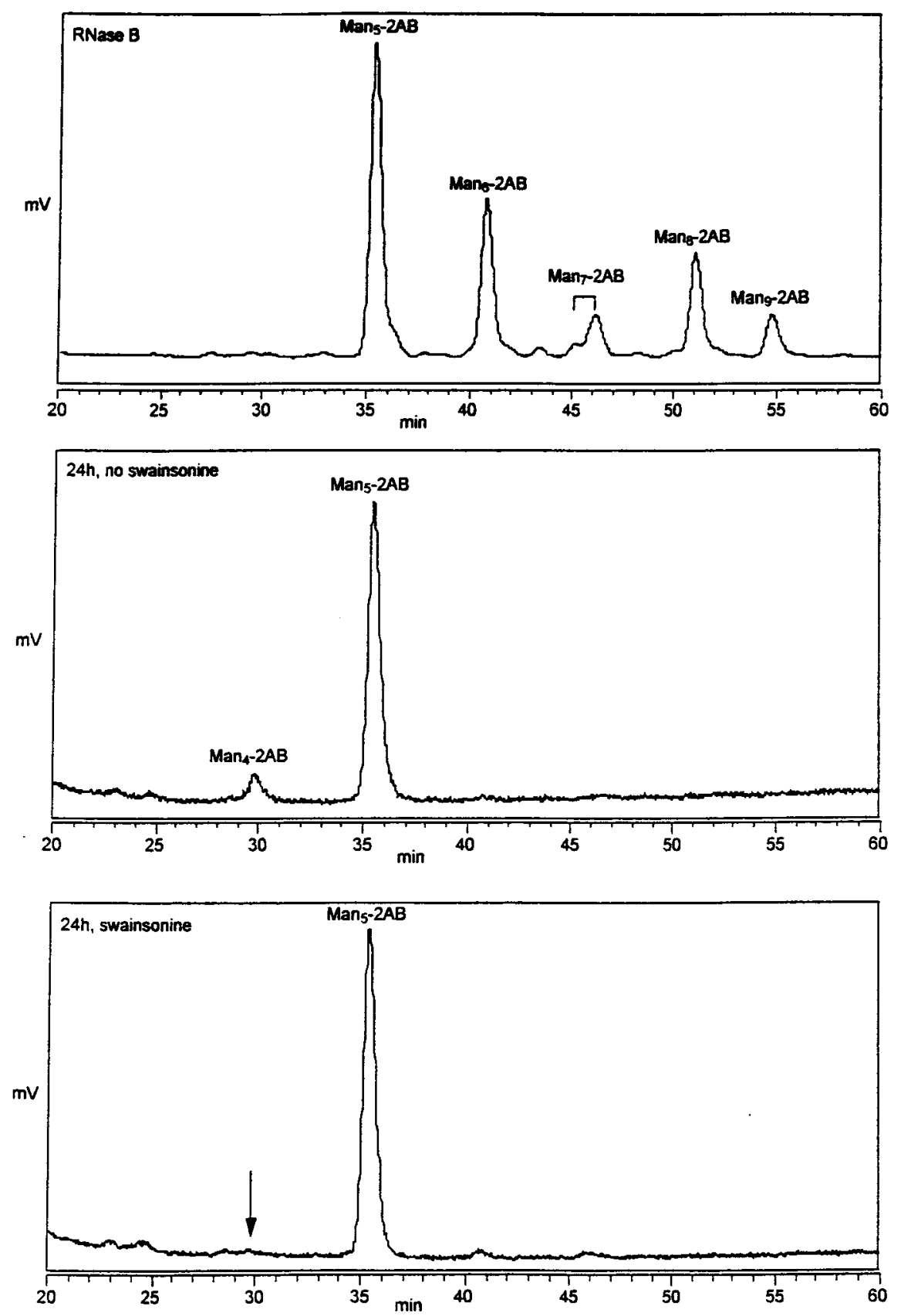

FIG. 4. HPLC profiles of a $2 A B$-labeled oligomannose-type glycan standard derived from RNase $B$ (upper panel), $M a n_{5} G I C N A C_{2}-2 A B$ after $24 \mathrm{~h}$ incubation with $A 431$ cells in the absence of swainsonine (middle panel), and $\mathrm{Man}_{5} \mathrm{GICNAC}_{2}-2 \mathrm{AB}$ after $24 \mathrm{~h}$ incubation with A431 cells in the presence of swainsonine (lower panel). The arrow in the lower panel indicates the elution position of $\operatorname{Man}_{4} \mathrm{GICNAC}_{2}-2 \mathrm{AB}$.

Whether the absence of $\alpha$-mannosidase III is exemplary for human cells, for cancerous cell lines, or for epithelial cells has still to be answered. Furthermore, its absence was reported before in $A$. aegypti mosquito cells (18). Even when an $\alpha$-mannosidase III activity is present, it does not necessarily lead to the production of complex-type $\mathrm{N}$-glycans on glycoproteins, as was shown in BHK cells $(18,21)$. The absence of $\alpha$-manno- sidase III activity in A431 cells, therefore, argues against the $\mathrm{Man}_{5}$ hydrolase activity of $\alpha$-mannosidase III as a general or major feature.

\section{ACKNO WLEDGMENT}

We thank Helgard Lengyel for her help with the mannosidase activity assay. 


\section{REFERENCES}

1. Kornfeld, R., and Kornfeld, S. (1985) Annu. Rev. Biochem. 54, 631- 664.

2. Elbein, A. D. (1991) FASEB J . 5, 3055-3063.

3. Bozon, D., Tarentino, A. L., Trimble, R. B., and Maley, F. (1986) Arch. Biochem. Biophys. 249, 546-556.

4. Asada, M., Furukawa, K., Kantor, C., Gahmberg, C. G., and Kobata, A. (1991) Biochemistry 30, 1561-1571.

5. Chui, D., Oh-Eda, M., Liao, Y.-F., Panneerselvam, K., Lal, A., Marek, K. W., Freeze, H. H., Moremen, K. W., Fukuda, M. N., and Marth, J. D. (1997) Cell 90, 157-167.

6. Bonay, P., and Hughes, R. C. (1991) Eur. J. Biochem. 197, 229-238.

7. Günther, N., Betzel, C., and Weber, W. (1990) J . Biol. Chem. 265, 22082-22085.

8. Kamerling, J. P., and Vliegenthart, J . F. G. (1989) in Clinical Biochemistry-Principles, Methods, Applications: Vol. 1, Mass Spectrometry (Lawson, A. M., Ed.), pp. 176-263, de Gruyter, Berlin.

9. Bergwerff, A. A., Stroop, C. J . M., Murray, B., Holtrof, A.-P., Pluschke, G., van Oostrum, J ., Kamerling, J . P., and Vliegenthart, J . F. G. (1995) Glycoconjugate J . 12, 318-330.

10. Geyer, R., Geyer, H., Kühnhardt, S., Mink, W., and Stirm, S. (1983) Anal. Biochem. 133, 197-207.
11. Bigge, J . C., Patel, T. P., Bruce, J . A., Goulding, P. N., Charles, S. M., and Parekh, R. B. (1995) Anal. Biochem. 230, 229238.

12. Guile, G. R., Rudd, P. M., Wing, D. R., Prime, S. B., and Dwek, R. A. (1996) Anal. Biochem. 240, 210-226.

13. Hård, K., van Zadel hoff, G., Moonen, P., Kamerling, J . P., and Vliegenthart, J. F. G. (1992) Eur. J. Biochem. 209, 895915.

14. Stroop, C. J . M., Weber, W., Gerwig, G. J ., Nimtz, M., Kamerling, J . P., and Vliegenthart, J . F. G. (1999) Submitted for publication.

15. Bendiak, B., Orr, J ., Brockhausen, I., Vella, G., and Phoebe, C. (1988) Anal. Biochem. 175, 96-105.

16. Hård, K., Mekking, A., Kamerling, J . P., Dacremont, G. A. A., and Vliegenthart, J . F. G. (1991) Glycoconjugate J . 8, 17-28.

17. Weisshaar, G., Hiyama, J ., and Renwick, A. G. C. (1991) Glycobiology 1, 393- 404.

18. Monis, E., Bonay, P., and Hughes, R. C. (1987) Eur. J . Biochem. $168,287-294$.

19. Tulsiani, D. R. P., Hubbard, S. C., Robbins, P. W., and Touster, O. (1982) J . Biol. Chem. 257, 3660-3668.

20. Elbein, A. D., Solf, R., Dorling, P. R., and Vosbeck, K. (1981) Proc. Natl. Acad. Sci. USA 78, 7393-7397.

21. Foddy, L., Feeney, J ., and Hughes, R. C. (1986) Biochem. J . 233, 697-706. 